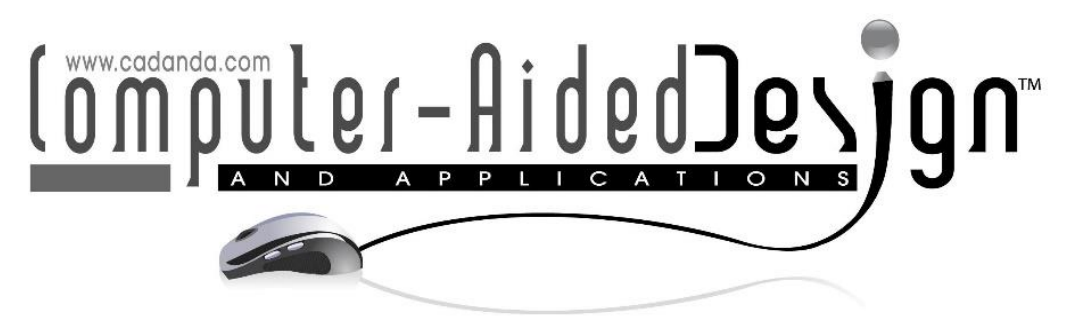

\title{
Research on Product Primitives Recognition in a Computer-aided Brand Product Development System
}

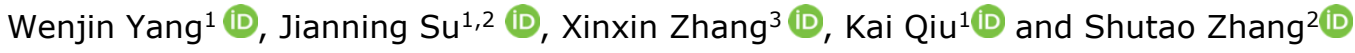 \\ ${ }^{1}$ School of Mechanical \& Electronical Engineering, Lanzhou University of Technology, \\ 171080203016@lut.edu.cn; 191080203003@lut.edu.cn \\ ${ }^{2}$ School of Design Art, Lanzhou University of Technology,zhangsht@lut.edu.cn \\ ${ }^{3}$ School of Architecture and Art Design, Hebei University of Technology, \\ y10160052@mail.ecust.edu.cn
}

Corresponding author: Jianning Su, sujn@lut.cn

\begin{abstract}
When developing new products, brand designers must analyse related products, which is a complicated and time-consuming process. Modern product design often requires complex engineering processes; product development requires extensive knowledge but there is also a demand for shorter product design cycles. Therefore, we propose a method based on extension theory and the analytic hierarchy process for identifying product-related knowledge, to aid the development of new products. First, based on our understanding of extenics, matter-element and relational meta-models of product form, function, and structure are established. Then, we define different primitives of brand identity. Finally, using an "extensional analytic hierarchy process" (EAHP), a hierarchy is established and the weights of different primitives are calculated. Various combinations of primitives are used to facilitate knowledge transfer for computer-aided intelligent design. Design data for multiple cases are analysed to verify the feasibility and effectiveness of the method. The method was verified in a physiological signal experiment, and the results show that the method can effectively accumulate product knowledge. Rapid data mining is important for market competitiveness.
\end{abstract}

Keywords: Brand identity, Knowledge transfer, Extenics, EAHP, Computer-aided intelligent design

DOI: https://doi.org/10.14733/cadaps.2021.1146-1166

\section{INTRODUCTION}

Manufacturing plays a fundamental role in all national economies [34]. Knowledge is key for productivity and the application of intelligent manufacturing is rapidly increasing [32]. Product design accounts for the majority of the production costs [3]. Product complexity is continually increasing and new products often have many integrated features; greater knowledge is required but there is also a demand for shorter product design cycles [5]. Knowledge-based design methods 
greatly enhance competitiveness [6]. However, beyond the macro level (modeling and materials), it is essential that product components be compatible among generations at the micro level. Zhang et al. [42] developed a morphological knowledge push technique based on probability matching, design knowledge, context and content. Fu et al. [12] developed a "product family DNA" method for visual identification of brands in an industrial design context. Giovannini et al. [14] presented an algorithm for knowledge representation, based on the logical structure of grammar mapping, to remove ambiguities in knowledge transfer. Ma et al. [29] proposed a decision-tree learning algorithm that reduces uncertainty in human decision-making, by identifying "useful uncertainties" during knowledge transfer. The most important issues in computer-aided intelligent design are the acquisition, expression, storage, management, and analysis of design knowledge [18]. Zhao [44] established a conceptual design model based on extenics for solving the contradiction problem in the context of knowledge transfer. Fougères et al. [11] combined observation, decision, and action knowledge in their model for the design of basic geometric objects. In the model, communication and reasoning are based on shape grammars, and dynamic objects are produced through division and multiplication.

Although current intelligent-design methods have proven effective, there is still a lack of systematic models that can effectively handle design knowledge [13]. The "law of creative activity", which is operative during upstream design, has received little attention, and few methods effectively handle innovation and dialectical thinking [15]. Extenics uses a formal language to describe expansion, novelty, and innovation, and can handle design logic. Hence, we use extenics and related methods, beginning with the ideas of designers and engineers and, based on the concept of product primitives, we propose a method for solving the contradictions and conflicts associated with product brand recognition using computer-aided intelligent design. Compared with the traditional analytic hierarchy process, the theory has both qualitative and quantitative aspects, and improves the utility of computer-aided intelligent design with respect to innovation and problem solving.

\section{THEORETICAL BACKGROUND AND RELATED RESEARCH}

\subsection{Brand Identity}

Brand identity is of fundamental importance for all new products. Product design and development require distributed collaboration. Designers must consider product characteristics and constraints at various levels [9]. To create a strong brand identify, a steady stream of new ideas is needed, while conforming to the brand's history and culture [38]. Brands tend to be based on certain semantic rules and combinations of shapes [33]. Certain style design elements give rise to brand recognition. For example, Volvo cars feature solid "shoulder" lines and V-shaped hoods on the rear fenders and front grilles, projecting a "safe" and "strong" image. Brand identity is based not only on physical appearance but also on user experience [35]. Designers often create brand identity by repeatedly using certain morphological elements [36]. Luo et al. [28] defined brand identity as a set of unique associations that brand designers create or maintain. Lieven [25] defined brand identity in terms of the synthesis of visual and verbal elements that support, express and communicate, the brand. For example, brand identity may be based mainly on shape (e.g. the Apple iPod) or colour (e.g. yellow for Kodak and red for Coca-Cola). To maintain brand identity, Bohm [4] developed a method for quantifying consistency in design elements across products. Using their method, new products can be evaluated in terms of their similarity to previous designs. Cheutet [8] divided the cars of one manufacturer into 10 design elements, and expressed the similarities between those elements in terms of Euclidean distances. A new design was then synthesized based on shape grammars. To understand brand recognition in terms of design intent and user response, Hyun [22] used Fourier decomposition to analyse the similarities among 23 brands of cars, and ranked car design elements based on the results of eye tracking experiments. Randle [31] stated that components must represent and strengthen brand identity and that brands must evolve in a conservative manner so that brand recognition among customers remains high. Thus, every brand should retain certain core elements [19]. A brand should also express the cultural characteristics of a specific region [2]. For 
example, Peugeot, Citroen, and Renault are French car brands, while Volkswagen is a German brand, Jaguar is a British brand and Cadillac is an American brand; these brands should reflect the culture of their countries of origin [35]. However, maintaining brand identity in the face of globalization and cultural mixing is challenging [20]. It has been suggested that certain symbols should be included in all products and lines of a given brand to maintain brand image. Symbols can be defined as explicit, qualitative, or implicit, and provide information on the overall brand; product lines, and product function and structure, respectively. Using this framework, Hyun [16] distinguished among different automobile designs. Bluntzer et al. [1] also identified various design symbols. In this study, we analysed the cognitive processes of brand designers, and distinguished among "brand", "adaptable", and "personality" elements. Of these, brand symbols reflect the entire product design, and play a key role in maintaining brand stability. Adaptability symbols can change with a change in the product platform, and are scalable and flexible. Individualized symbols produce different brand forms.

\subsection{Extenics}

Extenics formally describes objectives and things, and explores possible expansions and the law of innovation in play during expansion. Extenics embraces primitive, extension-set, and extension-logic theory, and is flexible, simple, and uniform [39]. Qian et al. [30] used the "extensional analytic hierarchy process" (EAHP) to analyse the contribution of each coupling element to a functional system; this identified the primary and secondary sequences of the elements. Zou et al. [46] established a part-variant matter-element model by fusing the geometric structure, function, and semantics of a part to those of its substructures, and showed that the model effectively supported appropriate variations of the product form. Li et al. [23] developed a form of multi-level extension genetic reasoning, which better solved problems for which innovation and functionality could not be simultaneously considered.

Primitive theory collects the values of things, the things per se, and their related characteristics into triplets [10]. A primitive element is the smallest unit of extenics, represented by the symbol X, including matter elements and a relation element. Form as a way of manifesting a thing is the object of this research.

\subsubsection{Matter definition}

Reflecting the needs of brand recognition, the morphological elements are divided into three categories: brand, adaptable, and personality elements. Suppose that a shape is termed $N$, a feature $C$, and the multiple corresponding feature values the $V s$. Then, the matter element $M$ is expressed as:

$$
M=\left\{\begin{array}{lll}
N & c_{m 1} & v_{m 1} \\
& c_{m 2} & v_{m 2} \\
\vdots & \vdots \\
& c_{m n} & v_{m n}
\end{array}\right\}
$$

Of these, the brand element is the key design language of the entire branded product series, playing a key role in maintaining brand stability, enabling consumers to generate the form elements of the brand association. Adaptable elements change with different product platforms. They are scalable and flexible. An individuality element refers to the unique morphological knowledge of different individuals in terms of branded products. Such knowledge is diverse and multi-dimensional, and plays a key role in determining the extent of innovation.

\subsubsection{Affair definition}

Suppose an action is termed $O$, a feature $C$, and the multiple corresponding feature values $V s$. Then, the affair element $A$ is expressed as: 


$$
A=\left\{\begin{array}{lll}
O & c_{a 1} & v_{a 1} \\
& c_{a 2} & v_{a 2} \\
\vdots & \vdots \\
& c_{a n} & v_{a n}
\end{array}\right\}
$$

Reflecting the needs of brand recognition, we divide event-element models into two categories: fixed and extension event elements. A fixed event element refers to the functional structure or usage mode imposed by the requirements of the branded product's performance. Such elements are very stable, and the external form of the product must be adapted to the element. Extension events refer to the functional structure or usage modes of a product with flexible characteristics, and are (to an extent) random.

\subsubsection{Relational element definition}

Suppose the relationship between two elements is termed $O r$, the feature is termed $C$, and the multiple corresponding feature values as $V s$. Then, the relational element $R$ is expressed as:

$$
R=\left\{\begin{array}{lll}
O_{r} & c_{r 1} & v_{r 1} \\
& c_{r 2} & v_{r 2} \\
& \vdots & \vdots \\
& c_{r n} & v_{r n}
\end{array}\right\}
$$

Reflecting the needs of brand recognition, we divide the relational meta-models into two categories: fixed and extensional relational elements. A fixed relational element refers to an inherent partmatching relationship; the external form of the product must be adapted to this element. An extensional relational element features part- matching with flexible characteristics of the product, and may vary to some extent.

Based on the above three basic elements, complex elements are constructed to describe more complex things. A complex element is composed of matter elements and relational elements. When primitives are used to describe things, expand analysis, and explore extensibility (implications, divergence, expansion, and correlation), new (and relevant) design knowledge and information are created, enhancing the ranges of morphology and function. Here, we extend primitives to obtain the extension intervals of product form, function, and co-operation, guiding the subsequent identification of product primitives.

\subsection{The Analytic Hierarchy Process}

The analytic hierarchy process [37] (AHP) is a method used to comprehensively evaluate things that employ multiple criteria. In essence, it recognizes that people decompose complex problems into multiple levels and elements, form a hierarchical structure dictated by the dominant relationship, and comprehensively consider the weight of each factor to select the best scheme. Many classical AHPs have been developed, including the Fuzzy (F) AHP [7] and the Extension (E) AHP [30]. Kumar et al. [21] evaluated the overall performance expected by customers based on the design scheme. Preference rankings were combined with ideal solution rankings using an AHP to form a multicriterion decision-making method that identifies the best design plan, thus the most reasonable choice. This intelligent decision-making method is very useful from the perspectives of both the customer and the manufacturer. Lin et al. [26] proposed a framework that combined an AHP with the similarity-ranking technology of an ideal scheme, allowing designers to identify customer needs and design characteristics and effectively evaluate the final design. To identify design patterns and user experiences, Li et al. [24] employed a group decision method that used an AHP to weigh userexperience preferences. The method improves user-experience quality, and serves as a universal user-experience optimization method.

Here, we combine an AHP and Extension Set Theory to develop a Design Extension (DE) AHP to identify design knowledge. We establish a brand recognition calculation model based on extension 
domains that can determine the influence weights of product primitives on brand attribute recognition, to classify the types of product primitive accurately, and combine it with the concept of biological evolution to define the development process of each primitive. The evolutionary model in the product form provides a basis for implementing the evolutionary design in the subsequent product form using the intelligent design process.

\subsection{How Extenics Promotes Creative Thinking during Design}

The intelligent-design process is both complicated and fuzzy. Its development is inseparable from that of "thinking science". Improvements in the expression, analysis, and acquisition of morphological knowledge are inextricably linked to improvements in how people understand the world and how they think. With improvements in cognitive levels, the representation and analysis of morphological knowledge becomes closer to human thinking. Zhang et al. [43] used the matter and characteristic elements of extenics to establish an extension of an intelligent-design model. This complex system embraces static and dynamic design knowledge. Zhao [45] developed an intelligent, conceptual design research method based on extension theory, combining matter-element and fuzzy theory, and a genetic algorithm, to solve the problems of case-based reasoning and multi-objective optimization of conceptual design. Yang [40] proposed an intelligent-design concept based on matter-element dynamic system analysis, applied matter-element analysis methods to express the matter-element system of ceramic products, and developed an intelligent computer-aided conceptual design system for such products.

However, some problems remain. First, in terms of knowledge modeling, the matter-element model has not been extended to the design field, and, during computer-aided intelligent design, knowledge transfer remains incomplete and thus inadequate. Second, the creative thinking described by extenics is still not fully reflected in the models. Thus, we develop a product-primitive identification method for an intelligent-design system. This guarantees the transfer and re-use of brand knowledge. We add an expansion domain to the case reasoning of computer-aided intelligent design, and establish a brand-recognition hierarchy analysis structure based on a cognitive expansion domain. This ranks the weights of different components and primitives, solving the problems of insufficient redesign and subsequent optimization.

\section{METHODOLOGY}

In product-design research, product form and function knowledge are generally randomly inherited; important knowledge may be lost. It is essential to identify and categorize product primitives, engage in product evolution in different ways, and build multi-level knowledge-element re-use models to complete the reconstruction and sharing of cross-domain knowledge. This assists computer programs to effectively inherit the form knowledge, functional characteristics, and cultural spirit accumulated by a brand over the years. We build a product-primitive recognition model based on an EAHP to facilitate evolution in design.

\subsection{Method}

The specific research framework is shown in Figure 1:

Step 1. We perform data mining and analysis of company-related products via different channels, obtain product-related morphological and functional parameters, and the design team summarizes and categorizes products according to the general component classification model.

Step 2. Using the primitive theory of extenics, the form and functional components summarized above are subdivided into product primitives, and a hierarchical structure model is constructed.

Step 3. Based on matter-element divergence and the principle of product knowledge re-use, the form, function, behavior, and structure of the product are expanded using the original matterelements. In a product series, a feature is often shared by different products. In a product system, different products may have the same form components, functional units, and structural relationships. We collect products with the same hierarchical characteristics to obtain a product 
primitive divergent extension set (Figure 2). The cognitive processes of the designers are explored and the primitives are quantitatively expressed. An extension interval number judgment matrix is then constructed.

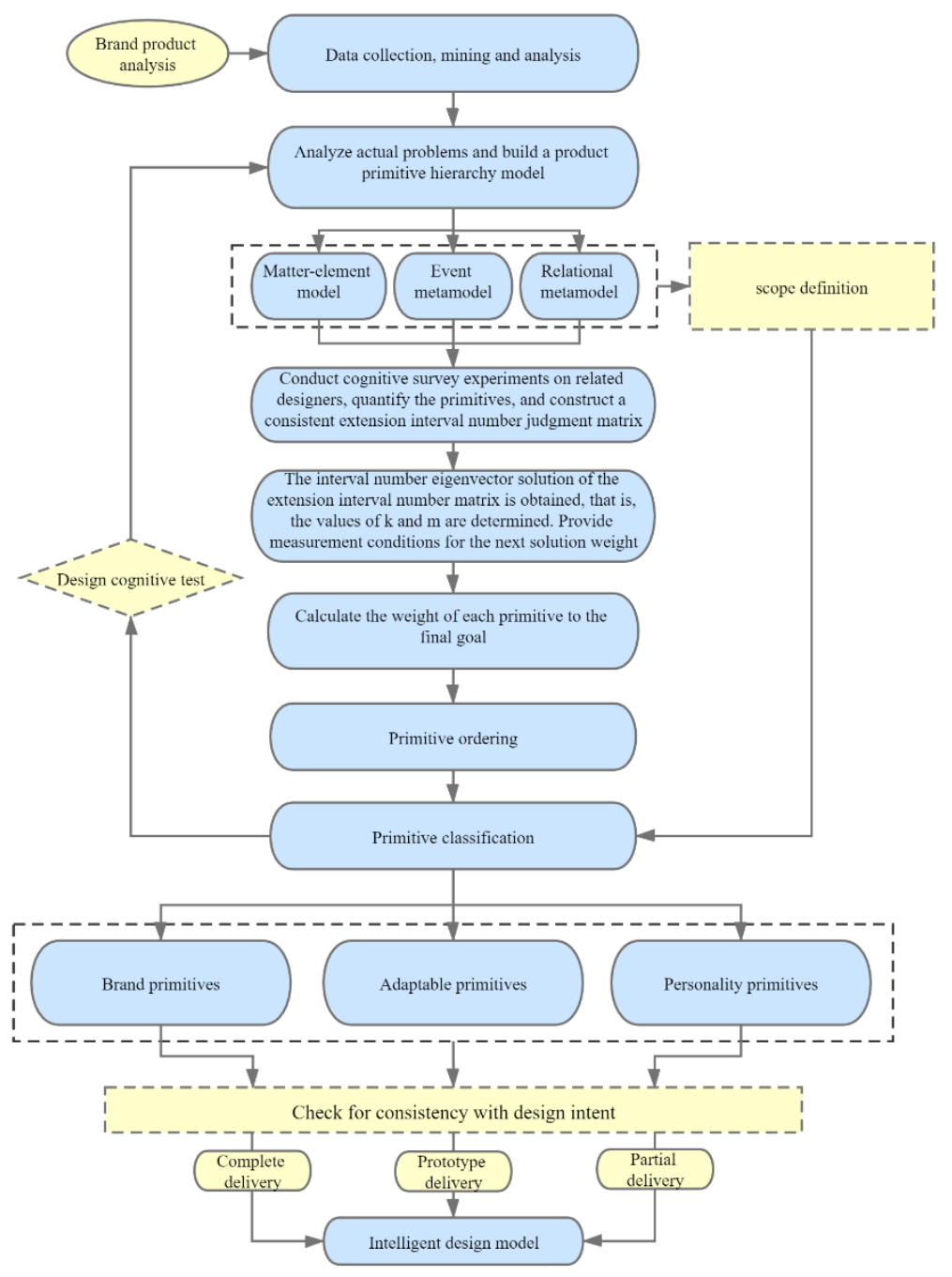

Figure 1. The research framework.

Step 4. Using a method that yields extension intervals and an EAHP to consider artificial judgment fuzziness, a judgment matrix is constructed to solve the "uncertain relative importance" problem. This method was proposed by Gao [17], who presented a detailed theoretical derivation and proof. In this method, the eigenvectors of the extension interval are solved and a consistency test is performed; this sets the measurement conditions for the next solution weighting.

Step 5. With brand recognition as the ultimate goal, we perform cognitive experiments to establish a hierarchical structure, and calculate the weight of each primitive in terms of its influence on the final goal.

Step 6. Using the weight ranking of the above primitives, the characteristics of each primitive are summarized according to their functional attributes; all primitives are sorted according to the weight of the above primitives and their characteristics are combined to divide the primitives into 
three types -brand primitives, adaptable primitives, and personality primitives - to facilitate crossmutation during computer-aided intelligent design.

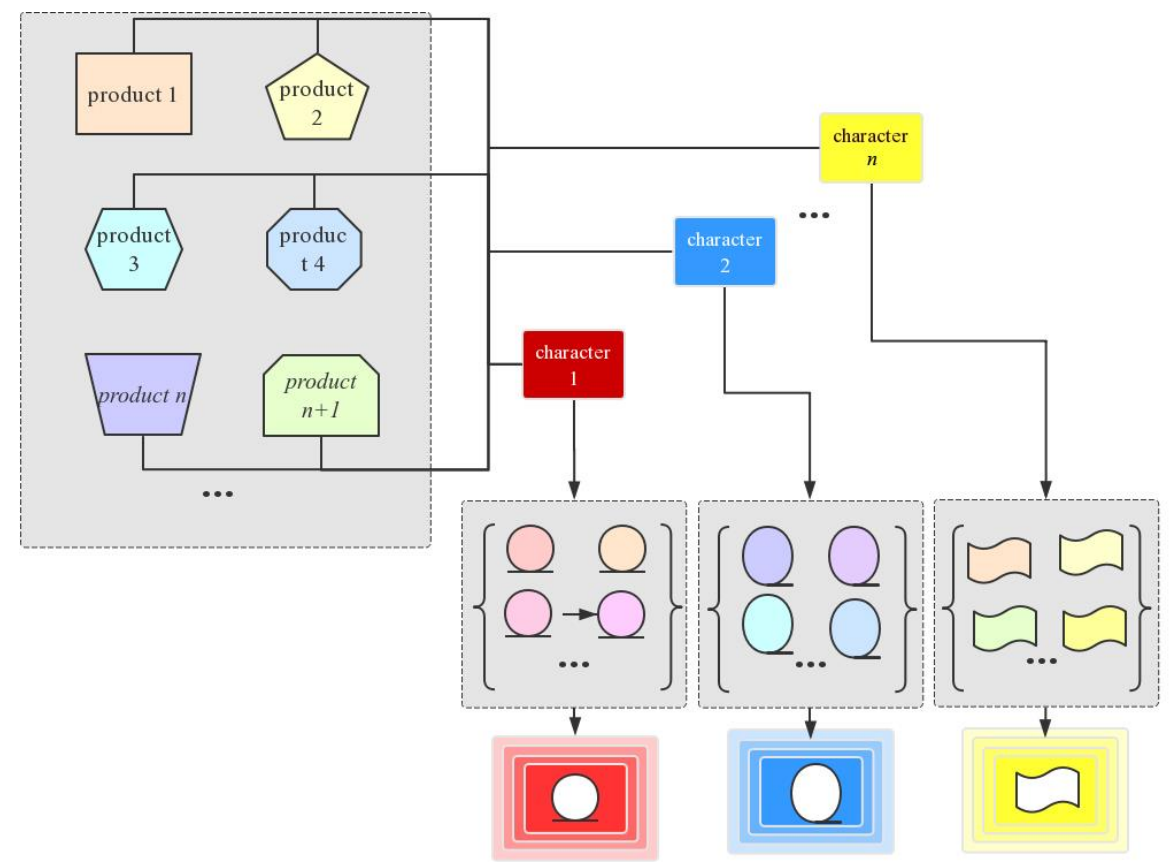

Figure 2. Product primitive divergent extension set.

\subsection{The Hierarchical Model}

Mutual relationships are in play among product substructures, with very strong relationships among the characteristic elements. The product form structure serves as the product function to a great extent. Therefore, a strong correlation is evident between product function and form elements, but certain contradictions are also apparent. To solve such problems, the relationships must be decomposed and summarized, and a hierarchical structure model that clearly analyses the problem obtained. Model-building commences from the perspective of cross-domain and multi-level knowledge reasoning, constructs a multi-level knowledge-element re-use model, and completes the reconstruction and sharing of cross-domain and multi-level knowledge. In any product system, product design is based on the design of the function that solves the physical structure; in other words, product-system modeling commences with function. Therefore, we use extension primitives to establish both form and functional product meta-knowledge models. This process employs a matter element, and the form element includes the function element and (to an extent) the relational element. For example, in 1891, the French put a car engine above the front wheels for the first time, and used the transmission to drive the rear wheels, producing the first front-rear-drive car. This structural change affected the appearance of all subsequent cars almost directly. We describe the product matter element and the matter element model as follows:

$$
R=\left[\begin{array}{rr}
\text { product, function, } I_{F} \\
\text { form, } & R_{M} \\
\text { behavior, } I_{B} \\
\text { structure, } R_{S}
\end{array}\right]=\left[\begin{array}{c}
F \\
M \\
B \\
S
\end{array}\right]
$$

Here, we use matter element I to represent function and a behavior or action, and matter element $\mathrm{R}$ to represent form or structure. Different product functions correspond to different behavioral states 
realized by different structures that in turn determine different forms. Mapping proceeds from one level to others. For example, when mapping structure to form, a single structure can be mapped to multiple forms, and a single form can correspond to one or multiple structural features. Using the relational model of extenics, the hierarchical structure relationship is shown in Figure 3.

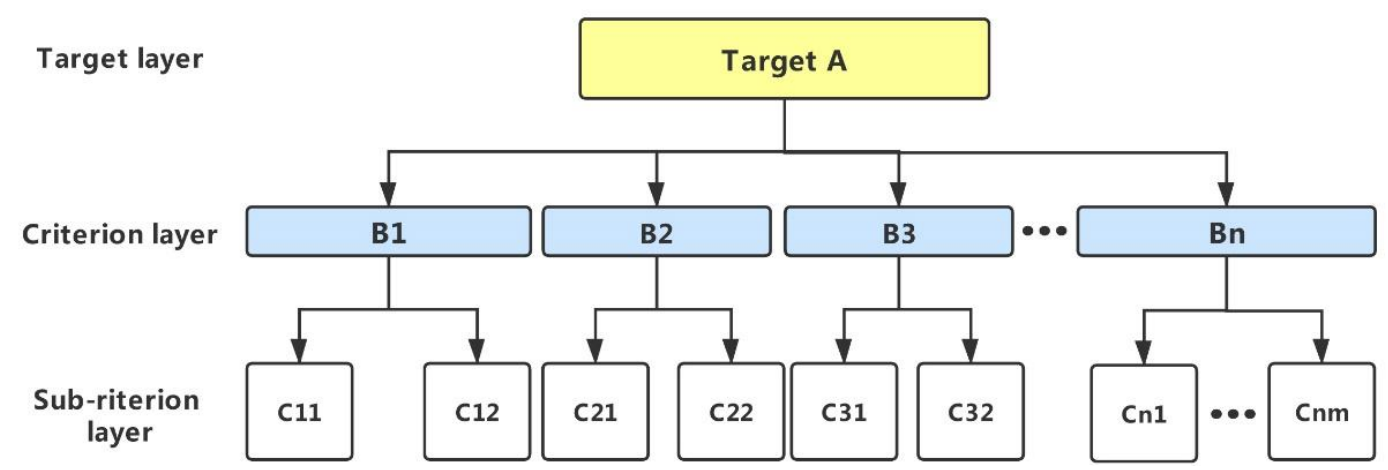

Figure 3. The hierarchical relationship structure.

\subsection{The Extension Interval Number Judgment Matrix}

We use an EAHP to study the effects of various morphological factors. For a specific product system, brand recognition is defined as the target level (the highest level), thus $A$; the part level is defined as the standard level (B); and the element level is defined as the factor level (C). We first obtain the single-item ranking weight vector of level $B$, and summarize the primitives into those that are more and less important. We then obtain the ranking weight vector of level $\mathrm{C}$ to determine how the weights of the different element forms in the brand product system affect the target problem (Figure 3). For example, designers considered the "kidney-shaped" grille and round headlights to be BMW's unique morphological style. Therefore, theoretically speaking, the grille and headlights are part of the process of BMW brand recognition and constitute an element with relatively high weight.

The principal steps are as follows: (1) Mining and collection of relevant research object data, and deconstruction of the research object. (2) Building the hierarchical structure of the research object by comparing the importance of all pairwise combinations of elements (we derive extended interval numbers to this end). Experts provide extension values using the rules of Table 1, and compare all pairs of elements twice. (3) Construction of the judgment matrix A (an orthogonal matrix) where $a_{i j}$ represents the comparison of the $i$-th factor with the $j$-th factor, where $\left(m_{i j}{ }^{-}+m_{1 i j}{ }^{+}\right) / 2=a_{i j}(i=1,2, \ldots, n ; j=1,2, \ldots, n ;)$ and $a_{i j}$ is the measure of importance. This yields an extended interval number judgment matrix $\left(M^{\prime}\right)$ which is a positive reciprocal matrix.

$$
M^{\prime}=\left[m_{i j}\right]_{n \times n}(i=1,2, \ldots n ; j=1,2, \ldots n)
$$

\begin{tabular}{|c|c|c|}
\hline Number & The pairs of values compared. & Meaning. \\
\hline 1 & 1 & The two factors are of equal importance. \\
\hline 2 & 3 & $\begin{array}{l}\text { The former factor is slightly more important } \\
\text { than the latter. }\end{array}$ \\
\hline 3 & 5 & $\begin{array}{l}\text { The former factor is somewhat more } \\
\text { important than the latter. }\end{array}$ \\
\hline 4 & 7 & $\begin{array}{l}\text { The former factor is more important than the } \\
\text { latter. }\end{array}$ \\
\hline 5 & 9 & $\begin{array}{l}\text { The former factor is much more important } \\
\text { than the latter. }\end{array}$ \\
\hline
\end{tabular}


6

$2,4,6,8$

The median values.

Table 1. The standard values.

\subsection{Solve for the Eigenvector}

We use the following formula to calculate the eigenvectors $k$ and $m$ :

$$
k=\sqrt{\sum_{j=1}^{n} \frac{1}{\sum_{i=1}^{n} m_{i j}^{+}}} \quad m=\sqrt{\sum_{j=1}^{n} \frac{1}{\sum_{i=1}^{n} m_{i j}^{-}}}
$$

\subsection{Calculate the Weight of Each Element in Terms of the Final Goal}

We geometrically average the row vectors of the matrix $M^{\prime}$ (using the square root method) and then normalize them to obtain the weight of each evaluation index and the feature vector $W$ :

$$
W_{i}=\bar{W}_{i} / \sum_{i=1}^{n} \bar{W}_{i} \quad W=\left\{\begin{array}{c}
w_{1} \\
w_{2} \\
\vdots \\
w_{n}
\end{array}\right\}
$$

\subsection{Extension Matrix Consistency Test}

This process prevents contradictory situations. For example, when $A$ is more important than $B$, and $B$ is more important than $C$, it is necessary to prevent situations in which $C$ is more important than A.

(1). We calculate the consistency index $C I=\frac{\lambda_{\max }-n}{n-1}$, where $C I=0$ indicates completely consistent; the greater the $C I$, the greater the inconsistency.

(2). We establish an average random consistency index set $R I$ as shown above, where $n=1$ to 10. The $R I$ set is generated using a random method as shown in Table 2.

\begin{tabular}{ccccccccccc}
\hline $\boldsymbol{n}$ & 1 & 2 & 3 & 4 & 5 & 6 & 7 & 8 & 9 & 10 \\
\hline $\boldsymbol{R I}$ & 0 & 0 & 0.58 & 0.90 & 1.12 & 1.24 & 1.32 & 1.41 & 1.45 & 1.49 \\
\hline
\end{tabular}

Table 2. The random consistency index.

(3). We calculate the consistency ratio $C R=\frac{C I}{R I}$; when $C I<0.1$; the consistency of the matrix is considered acceptable.

\subsection{Determine the Primitive Type}

Using the weights (calculated in the previous step) for product elements that determine brand recognition, each element is divided into three types of primitives, the most critical element, a secondary key element, and a general element. According to the needs of intelligent-design systems in terms of brand knowledge transfer, these are classified as brand, adaptable, and personality elements. According to the concept of biological evolution proposed by Darwin, the knowledge transfer mode of the subsequent intelligent design system for new product development is defined, and can be classified into brand, adaptable, and personality elements. 


\section{VERIFICATION}

Using New Holland brand tractors as an example, we establish a product primitive, hierarchical structure model that focuses on how the designer maintains the brand image. New Holland is one of the top 10 brands of tractors, specializing in the production and supply of wheeled tractors and small square balers. The company produces (principally) two tractor series, the T-series heavy-duty tractors and the Workmaster tractors (Figure 4, upper left). We used an EAHP to identify product primitives supporting front-end evolutionary design. This will assist expansion. The process is shown in Figure 4.

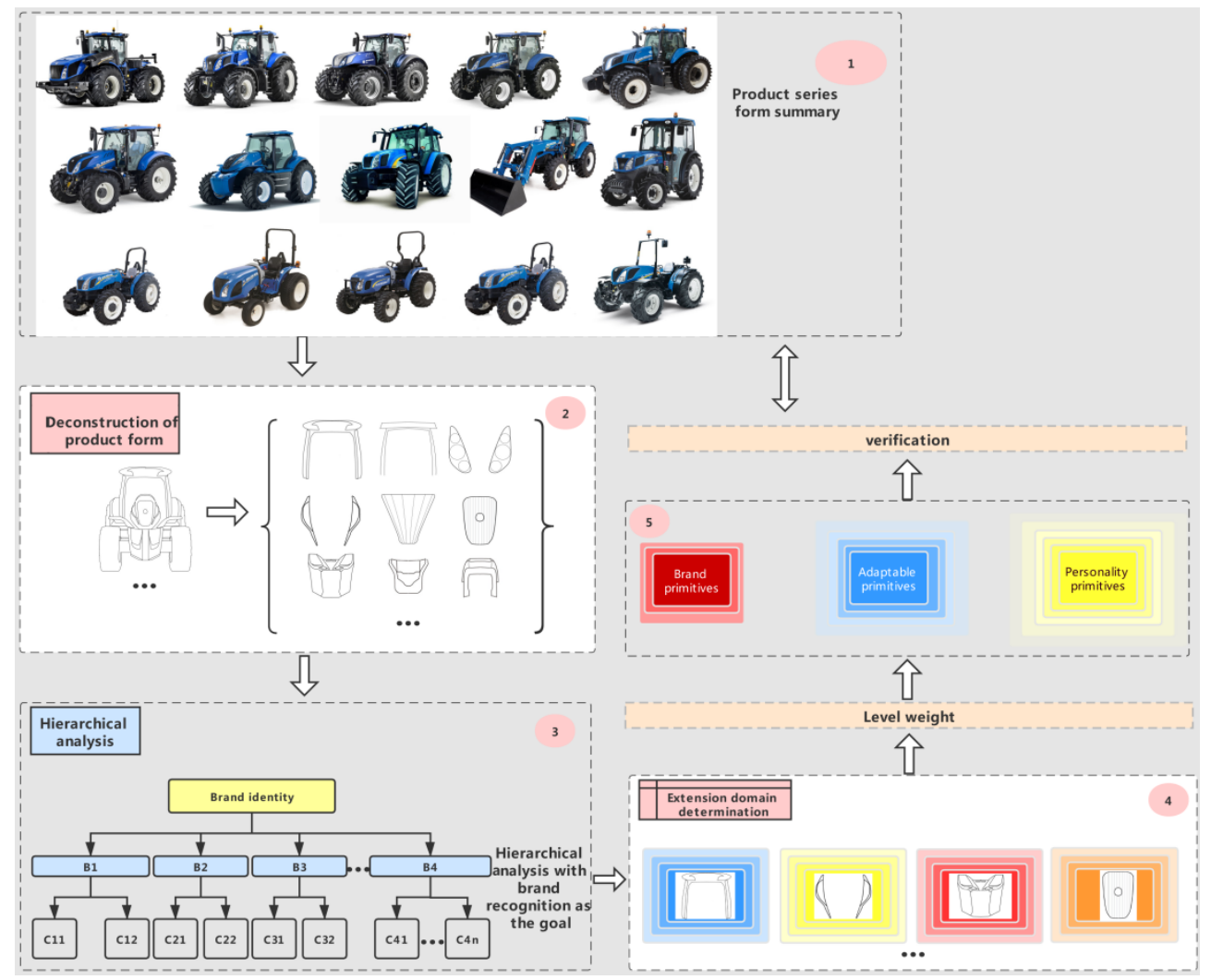

Figure 4. Implementation.

\subsection{The Hierarchical Model}

We used the method of 3.2 to build a hierarchical structure model, as shown in Figure 5 . Using the front profile of a tractor as the research object, the target layer was the extent of brand recognition of the tractor form, and the criterion layer was the tractor morphological component. For different parts of the form, the sub-criteria were the different subforms corresponding to the different parts.

\subsection{The Extension Interval Number Judgment Matrix}

Using our new methodology, we constructed an extension interval number judgment matrix using the "rule of the nine-unit preference scale" for product function. Twelve experts in product design research compared the relative importance of $\mathrm{N}$ indicators at the same level (in a two-by-two manner). The results of criterion-level interval scoring are shown in Table 3. 


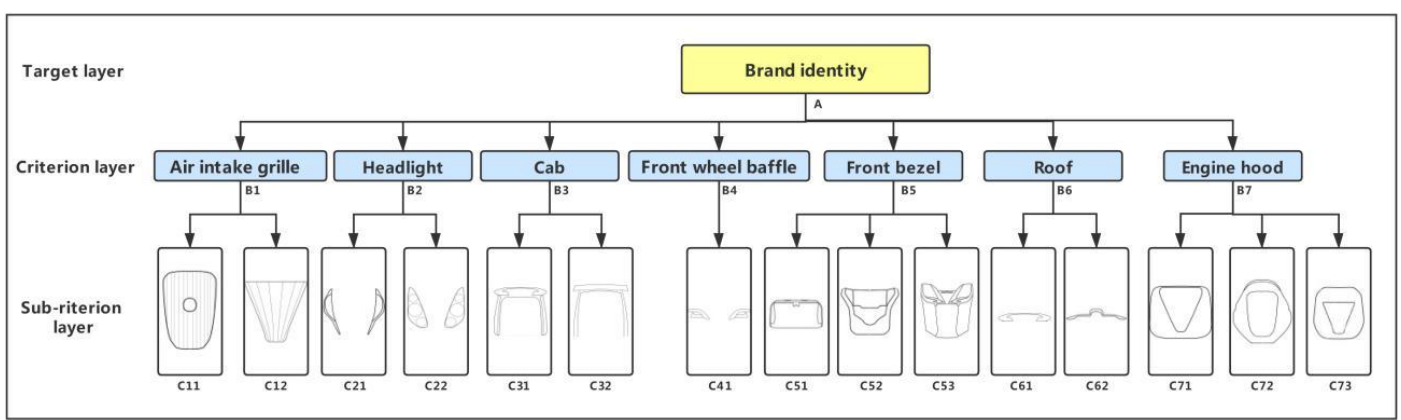

Figure 5. A hierarchical structure model of New Holland tractors.

\begin{tabular}{cccccccc}
\hline & $\begin{array}{c}\text { Air intake } \\
\text { grille } \\
(B 1)\end{array}$ & $\begin{array}{c}\text { Headlights } \\
(B 2)\end{array}$ & $\begin{array}{c}\text { Cab } \\
(B 3)\end{array}$ & $\begin{array}{c}\text { Front } \\
\text { wheel } \\
\text { baffle } \\
(B 4)\end{array}$ & $\begin{array}{c}\text { Front } \\
\text { bezel } \\
(B 5)\end{array}$ & $\begin{array}{c}\text { Roof } \\
(B 6)\end{array}$ & $\begin{array}{c}\text { Engine } \\
\text { hood } \\
(B 7)\end{array}$ \\
\hline $\begin{array}{c}\text { Air intake } \\
\text { grille (B1) }\end{array}$ & 1.00 & 2.67 & 3.83 & 6.67 & 4.00 & 4.67 & 1.33 \\
$\begin{array}{c}\text { Headlights } \\
(B 2)\end{array}$ & 0.37 & 1.00 & 2.67 & 5.33 & 3.17 & 2.17 & 0.00 \\
$\begin{array}{c}\text { Cab (B3) } \\
\text { Front wheel } \\
\text { baffle (B4) }\end{array}$ & 0.30 & 0.37 & 1.00 & 4.00 & 2.50 & 1.83 & 0.67 \\
$\begin{array}{c}\text { Front bezel } \\
(B 5)\end{array}$ & 0.25 & 0.32 & 0.40 & 1.33 & 1.00 & 2.00 & 0.35 \\
$\begin{array}{c}\text { Roof (B6) } \\
\text { Engine hood }\end{array}$ & 0.21 & 0.46 & 0.55 & 1.83 & 0.50 & 1.00 & 0.46 \\
$($ B7) & 0.75 & 0.00 & 1.50 & 4.00 & 2.83 & 2.17 & 1.00 \\
\hline
\end{tabular}

Table 3. Judgments of relative importance at the criterion level.

According to expert analysis, the extension interval number judgment matrix was:

$\mathbf{M}_{\mathbf{A}}=\left\{\begin{array}{lllllll}1.00 & 2.67 & 3.83 & 6.67 & 4.00 & 4.67 & 1.33 \\ 0.37 & 1.00 & 2.67 & 5.33 & 3.17 & 2.17 & 0.00 \\ 0.30 & 0.37 & 1.00 & 4.00 & 2.50 & 1.83 & 0.67 \\ 0.15 & 0.19 & 0.25 & 1.00 & 0.75 & 0.55 & 0.25 \\ 0.25 & 0.32 & 0.40 & 1.33 & 1.00 & 2.00 & 0.35 \\ 0.21 & 0.46 & 0.55 & 1.83 & 0.50 & 1.00 & 0.46 \\ 0.75 & 0.00 & 1.50 & 4.00 & 2.83 & 2.17 & 1.00\end{array}\right\}$

After verification, $C I<0.1$; the matrix thus passed the consistency test, and the one-way weight set relative to the target layer became:

$$
W^{(B)}=\left\{\begin{array}{l}
0.3464 \\
0.1791 \\
0.1265 \\
0.0420 \\
0.0742 \\
0.0689 \\
0.1629
\end{array}\right\}
$$




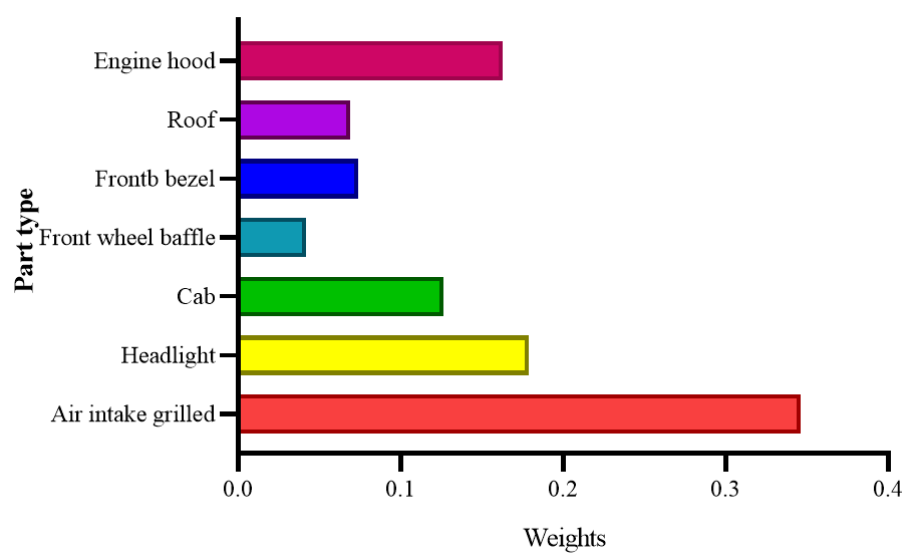

Figure 6. The weights of the different components.

As shown in Figure 6, in terms of brand recognition, the total weight of three components (the air intake grille, the headlights, and the hood) exceeded $60 \%$ of the overall weight; these were the most important elements. The cab, front wheel baffle, front baffle and roof were less important.

Employing the nine-unit preference scale for product function, the 12 experts compared the importance of indicators at the sub-criterion relative to the criterion level (in a two-by-two manner) (Table 4).

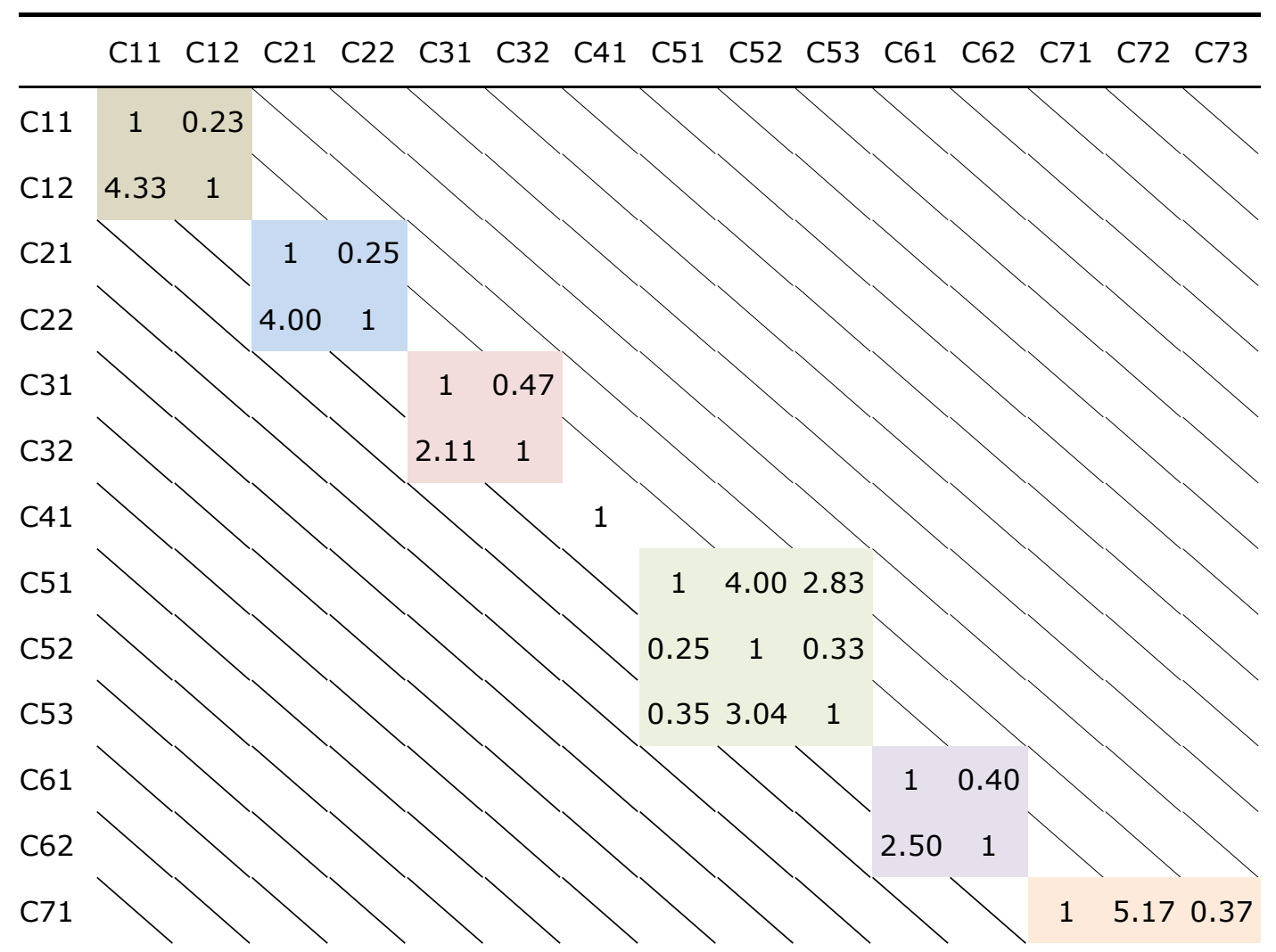




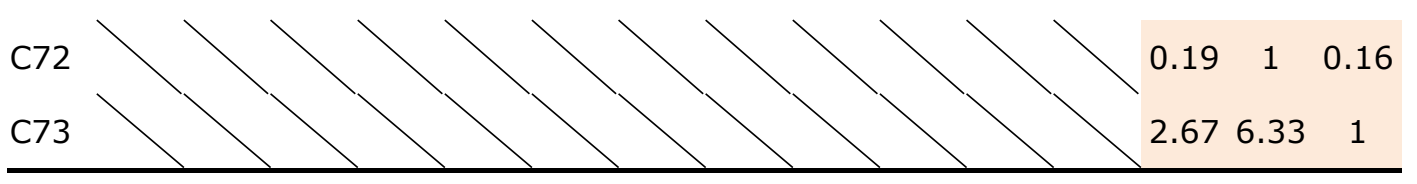

Table 4. The relative importance at the sub-criterion level.

The extension interval number judgment matrices for the different criterion levels were:

$$
\begin{aligned}
& \mathbf{M}_{\mathrm{B} 1}=\left\{\begin{array}{ll}
1 & 0.23 \\
4.33 & 1
\end{array}\right\} \quad \mathbf{M}_{\mathbf{B} 2}=\left\{\begin{array}{ll}
1 & 0.25 \\
4.00 & 1
\end{array}\right\} \quad \mathbf{M}_{\mathrm{B} 3}=\left\{\begin{array}{ll}
1 & 0.47 \\
2.11 & 1
\end{array}\right\} \\
& \mathbf{M}_{\mathbf{B} 5}=\left\{\begin{array}{lll}
1 & 4.00 & 2.83 \\
0.25 & 1 & 0.33 \\
0.35 & 3.04 & 1
\end{array}\right\} \quad \mathbf{M}_{\mathbf{B} 6}=\left\{\begin{array}{ll}
1 & 0.40 \\
2.50 & 1
\end{array}\right\} \quad \mathbf{M}_{\mathbf{B} 7}=\left\{\begin{array}{lll}
1 & 5.17 & 0.37 \\
0.19 & 1 & 0.16 \\
2.67 & 6.33 & 1
\end{array}\right\}
\end{aligned}
$$

$\mathrm{CI}<0.1$ for all matrices; all thus passed the consistency test; the calculated weight sets at the criterion level were:

$$
W_{1}=\left\{\begin{array}{l}
0.1725 \\
0.8275
\end{array}\right\} \quad W_{2}=\left\{\begin{array}{l}
0.2 \\
0.8
\end{array}\right\} \quad W_{3}=\left\{\begin{array}{c}
0.3206 \\
0.6797
\end{array}\right\} \quad W_{5}=\left\{\begin{array}{l}
0.6064 \\
0.1176 \\
0.2760
\end{array}\right\} \quad W_{6}=\left\{\begin{array}{l}
0.2857 \\
0.7143
\end{array}\right\} \quad W_{7}=\left\{\begin{array}{l}
0.3016 \\
0.0759 \\
0.6225
\end{array}\right\}
$$

\subsection{The Contribution of Each Element to the Final Goal}

We calculated the contribution of each element to the final goal using Eq. (5-7) to obtain the ranking and weight of each factor as $W^{(C)}$ (Table 5).

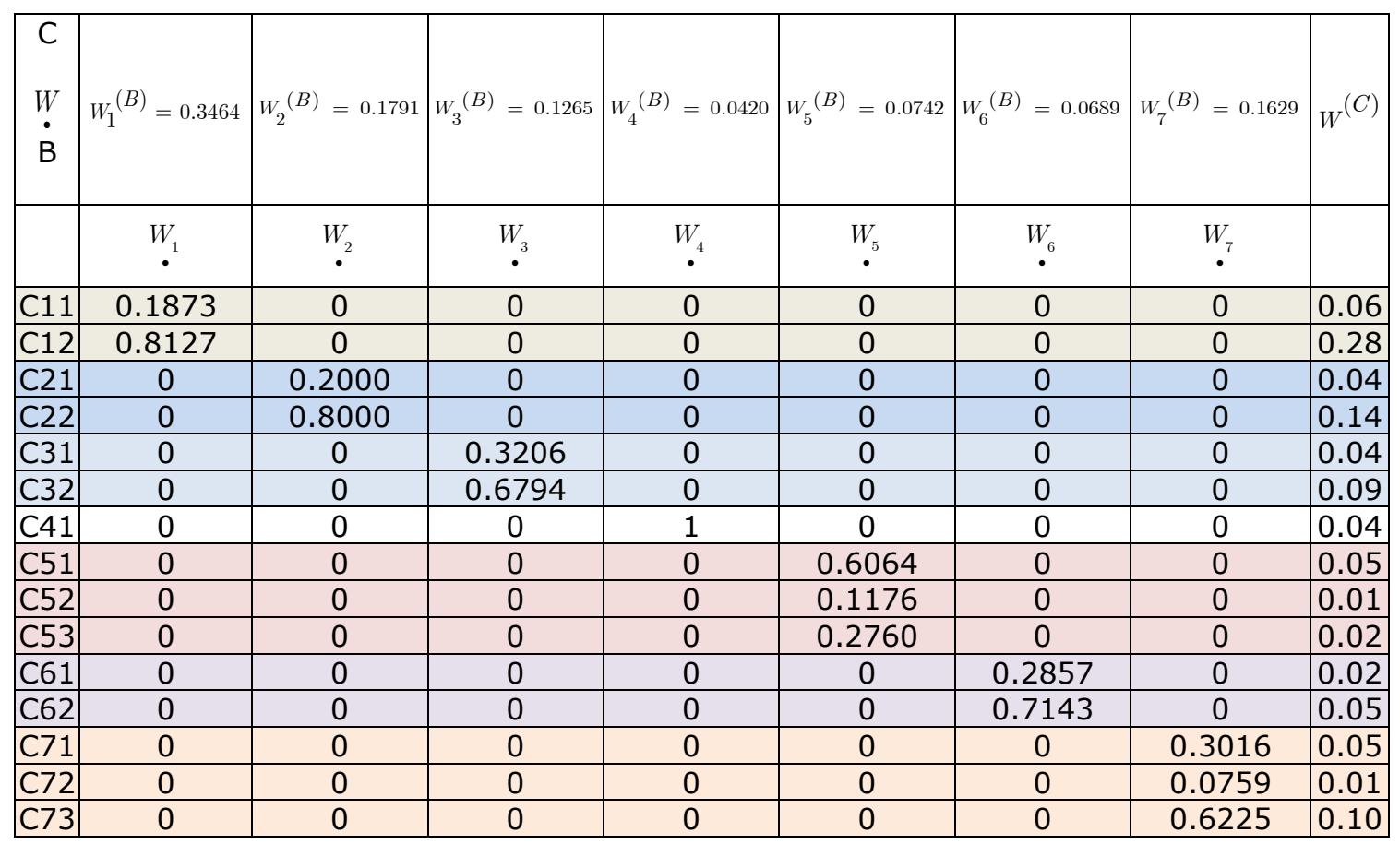

Table 5. The contribution of each element to the final goal. 


\subsection{The Primitive Types}

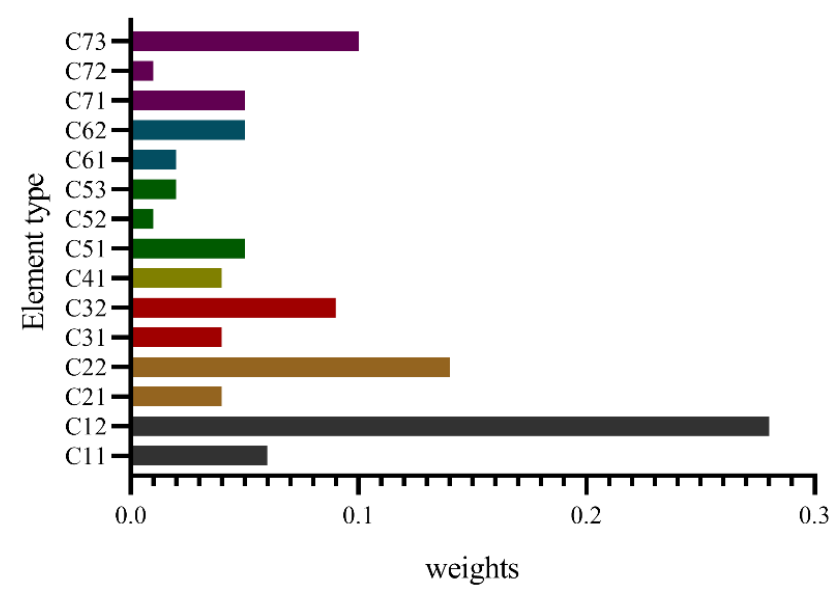

Figure 7. The weights of different primitives.

As shown in Figure 7, the contributions of $\mathrm{C} 12$ and $\mathrm{C} 22$ to brand recognition were significantly greater than those of the other elements. Therefore, C12 and C22 penetrated the entire life cycle of the brand. C73 and C32 lay in second place; their shapes were similar, while they varied by product function and model, and were thus adaptable elements. The remaining morphological features differed, and the weights were low; these were individual elements with larger extension domains, encouraging further diversification and individualization.

\subsection{Comparative Verification}

We performed two comparative verifications. First, we tested the consistency of the extension judgment matrix, thus, its logical consistency. For example, when $A$ is more important than $C$ and $B$

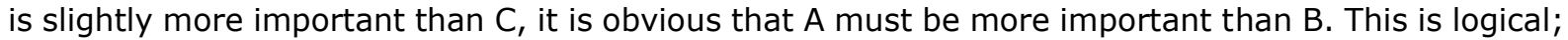
otherwise the judgment will be contradictory. The CI values of all matrices were less than 0.1 ; cognitive logic was in play.

Second, in our previous research [41], eye movement experiments are usually used to distinguish key elements from non-key elements. Therefore, in this study, we performed eye movement experiments on $15 \mathrm{New}$ Holland brand tractors using the same process. The eye movement experiments involved 13 participants, all of whom had design experience. Figure 8 shows the eye movement experiment heat map and eye movement index data output interface. The subjects' eye movement indicators, such as the duration of gaze, number of regains, and order of gaze, are counted. The results are shown in Table 6 . The importance of each morphology component is shown in Figure 9. We found that these results were basically consistent with the calculation results for the weight of each component in 4.2, which proves that the extension analytic hierarchy process has a degree of objectivity and accuracy from the perspective of physiological signals. However, these eye movement experiments required one-to-one collection of data from many designers, which takes a long time and can only distinguish relatively key elements. Concepts such as brand primitives, adaptable primitives, and personality primitives and their mode of transfer of morphological knowledge cannot be defined clearly.

Finally, we compared the results to the original intentions of the brand designer, who kindly sent us the design instructions (Figure 10). Indeed, the radical grille and the headlights represent and strengthen the New Holland brand identity. This verifies the feasibility and practicability of our method, which will aid the research and development of new branded products. 

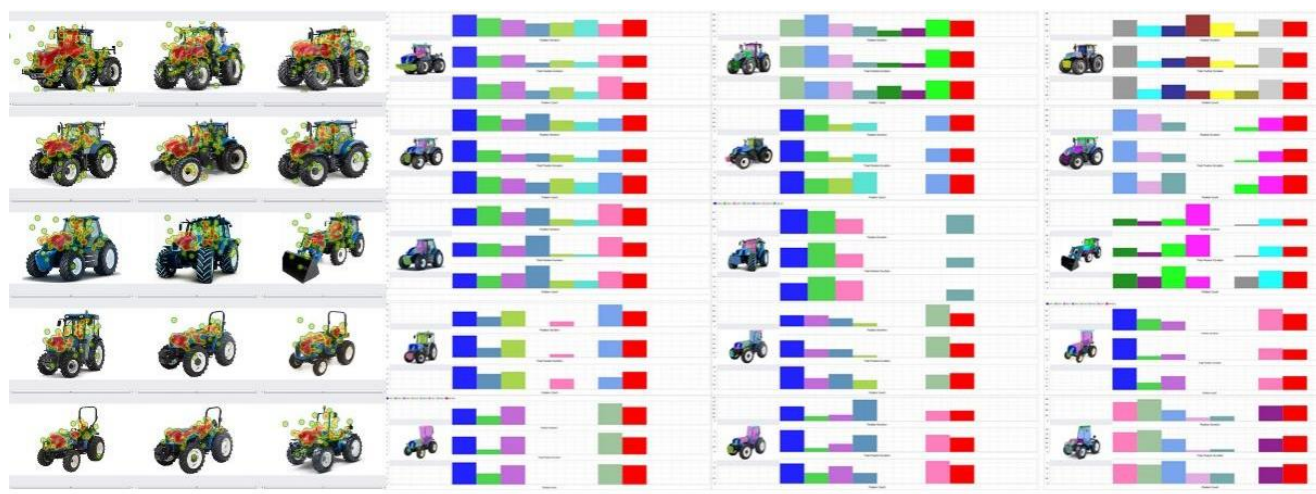

Figure 8. Eye movement heat map (left) Eye movement index data output interface (right).

\begin{tabular}{cccccccc}
\hline & $\begin{array}{c}\text { AOI1 } \\
\text { (Air intake } \\
\text { grille) }\end{array}$ & $\begin{array}{c}\text { AOI2 } \\
\text { (Headlights) }\end{array}$ & $\begin{array}{c}\text { AOI3 } \\
\text { (Cab) }\end{array}$ & $\begin{array}{c}\text { AOI4 } \\
\text { (wheel } \\
\text { baffle) }\end{array}$ & $\begin{array}{c}\text { AOI5 } \\
\text { (Front } \\
\text { bezel) }\end{array}$ & $\begin{array}{c}\text { AOI6 } \\
\text { (Roof) }\end{array}$ & $\begin{array}{c}\text { AOI7 } \\
\text { (Engine } \\
\text { hood) }\end{array}$ \\
\hline $\begin{array}{c}\text { Fixation Duration } \\
\text { Total Fixation }\end{array}$ & 0.74 & 0.67 & 0.46 & 0.18 & -0.39 & -0.41 & 0.68 \\
$\begin{array}{c}\text { Duration } \\
\text { Fixation Count }\end{array}$ & 0.74 & 0.67 & 0.46 & 0.16 & -0.45 & -0.47 & 0.70 \\
sum & 0.75 & 0.67 & 0.46 & 0.15 & -0.49 & -0.52 & 0.70 \\
\hline
\end{tabular}

Table 6. Results of related indicators of the eye movement experiment.

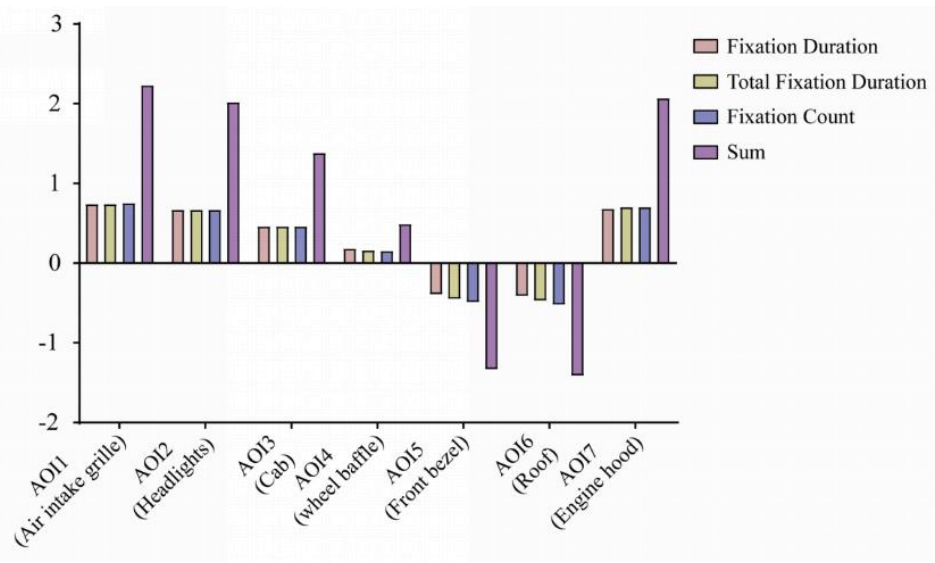

Figure 9. The importance of the various tractor parts.

\subsection{Additional Case Verification}

We take the product primitive identification research of the Joyoung brand soymilk machine as an example to verify this method again. First, as shown in Figure 11 (top), a product primitive hierarchy model based on the company's products is established. The corresponding weights of the component and primitive layers are calculated through DEAHP, and the calculation result is shown in Figure 11 (bottom). Furthermore, we classified the knowledge of the product primitives. We believe that, as 
typical elements, C32 (similar to a trapezoid cup) and C22 (rectangular nose) can run through the entire life cycle of the product's soymilk machine series.
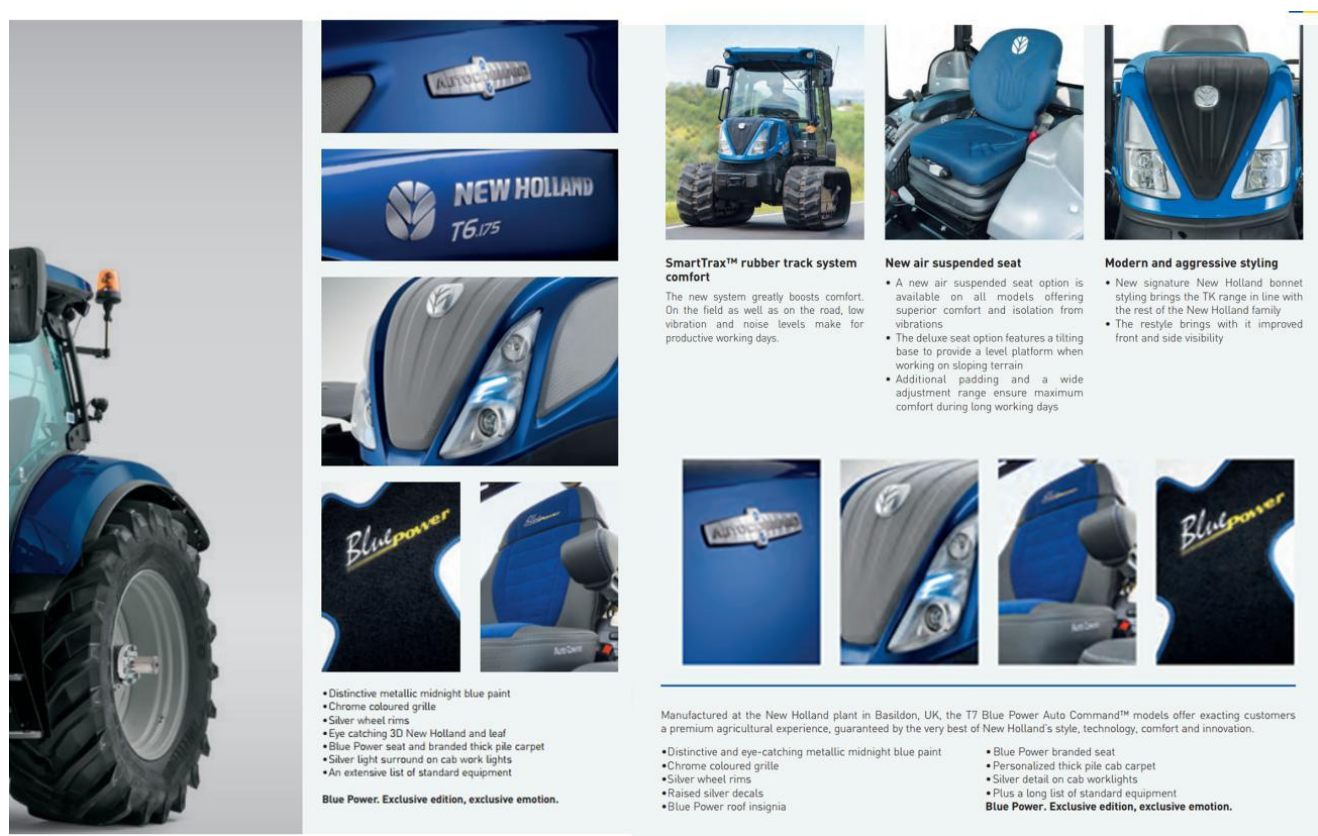

- The restyle brings with it improved
tront and side visibitity - working on sloping terrain
additional padment pang and a wide
comfort during long ensure maximum
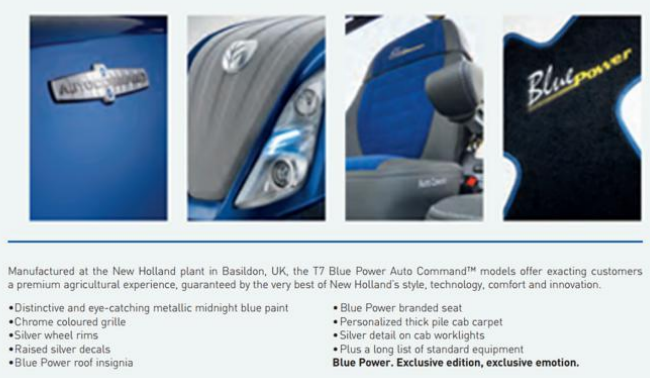

Figure 10. An extract of the New Holland tractor design description.

So, they are classified as brand primitives. The contribution of C44 (the more rounded Grip) is second, and its shape is similar to the shape of the same parts. They adapt the cup of the soymilk machine and produce changes, which are classified as adaptable primitives. The other morphological features have a greater degree of difference between each pair, and occupy less weight, so we classify the remaining primitives as individual primitives. We think that the extension domain of these personality meta-features is larger. They exist as the recognition of a certain individual feature and have great diversification and personalization. We also used an eye movement experimental model to verify this and the resulting ranks of the importance of each morphological component are shown in Figure 12.

The results of the above cases once again prove that the product primitive recognition model based on the extension analytic hierarchy process has high scientific value and wide practicability. Compared with eye movement experiments, this method can quickly classify product form elements and form knowledge for brand recognition, thereby establishing a front-end system that supports subsequent intelligent design.

\section{CONCLUSION}

During traditional product design, brand designers rely on their experience, while also collecting and analysing data on related product series to obtain brand knowledge. However, this is complicated and time-consuming. The extraction and effective inheritance of different types of knowledge are important [27]. We identified the knowledge needed when developing new products. We used an extenics-based hierarchical analysis structure. We calculated the one-way weight rankings of different components of brand recognition, and identified the more and less important design elements. We calculated all weights in terms of brand recognition, to derive the design intent, and finally obtained the primitive elements of the different categories. Via such quantitative decision- 
making, product form design is intelligent, and will assist later developments. Our specific contributions are:
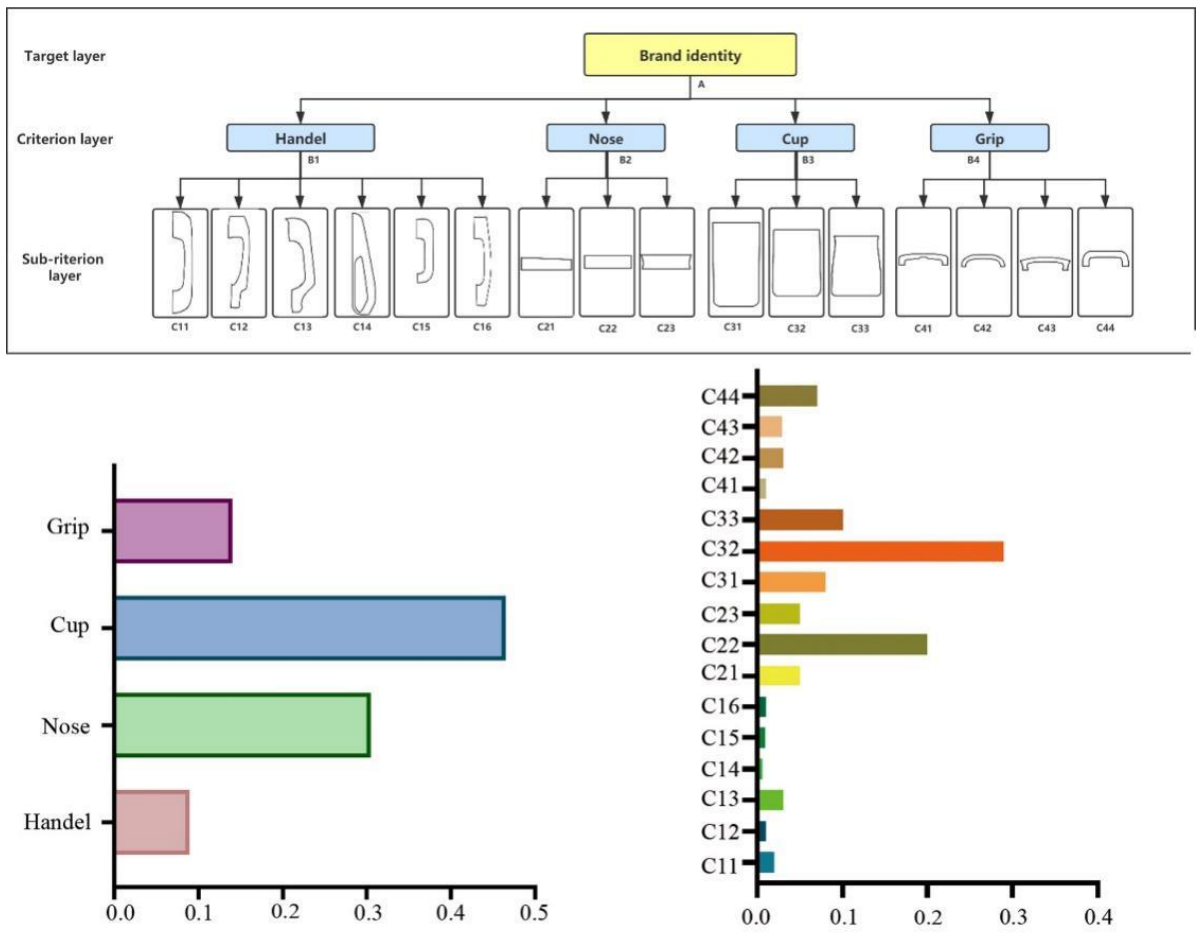

Figure 11. Hierarchical Model of a Soymilk Machine Brand (top). Weight of component layer (bottom left). Weight of primitive layer (bottom right).

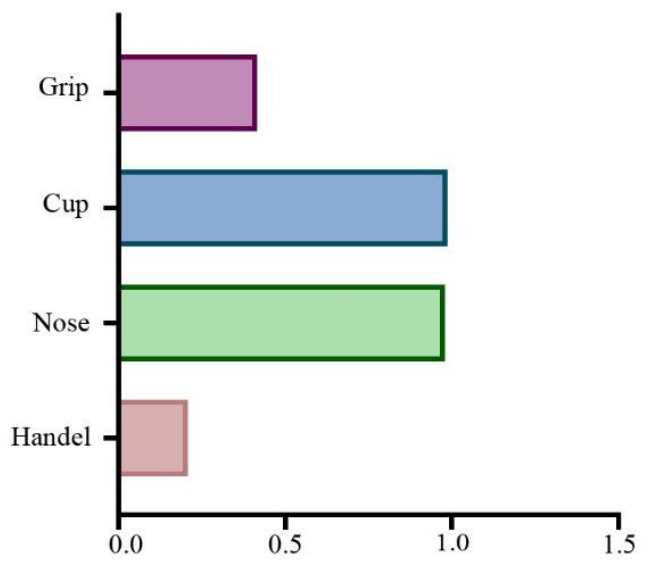

Figure 12. The importance of each component in the eye movement experiment.

1. Extension theory facilitates the reasoning process of design logic. A combination of such theory and an AHP hierarchy clearly and effectively reveals the structural relationships between design goals and morphological elements. From the perspectives of both designers and engineers, we offer solutions to the problems posed by product primitives and brand recognition during computer-aided intelligent design. 
2. The one-way weight ranking of extensional hierarchical analysis, thus the weight ranking of different components, will aid the design and development of new products. The overall weight ranking trends of morphological elements can serve as a reference for design evaluation. Various element forms can be effectively recorded, re-organized, expanded, and associated with other factors (such as a product structure) to develop a complete product form element database that serves as a reference for re-design and intelligent design.

3. We reformulated the knowledge transfer model in the subsequent new product development intelligent design system. Practically, designers can rationalize the evolutionary process based on the original form. Designers can also optimize the design to generate alternatives. Finally, designers can prioritize design elements during re-design.

4. Using the appearance of tractors and soymilk machines as case studies, DEAHP effectively identified product knowledge, strongly supporting brand serialization and design malleability, and providing designers with effective auxiliary tools. We verified the results obtained by DEAHP using the relevant index data of physiological signals, and verified the scientificity and practicality of the method. In comparison, DEAHP can acquire product form knowledge faster, to greater depth, and with more specificity. While we used tractors and soymilk machines as examples, the model can be applied to other products. More cases will be shown on the website http://productprimitivesrecognition.e.cn.vc/zh.

We scientifically combine qualitative and quantitative features. This reveals the expansion law in play during design, improving innovation and problem-solving. When a company re-develops a product, it is important to retain certain meta-types to ensure sensory recognition by consumers, and to shorten development time and reduce design costs. Our method can be a front-end knowledge recognition model linked to other intelligent-design systems for new product development. It is possible to integrate several different methods. Mutual method matching will be a focus of our future research. In addition, we will further explore how designers can effectively inherit product structure and functional knowledge.

\section{Acknowledgments}

This research was supported financially by the National Natural Science Foundation of China under Award numbers 51705226 and 51465037.

Wenjin Yang, https://orcid.org/0000-0002-8371-5831

Jianning Su, https://orcid.org/0000-0002-2409-9207

Xinxin Zhang, https://orcid.org/0000-0002-3037-0657

Kai Qiu, https://orcid.org/0000-0003-2071-4425

Shutao Zhang, https://orcid.org/0000-0003-4665-5443

\section{REFERENCES}

[1] Bluntzer, J.B.; Ostrosi, E.; Sagot, J.C.: Car Styling: A CAD Approach to Identify, Extract and Interpret Characteristic Lines, Elsevier B.V., 2014.

[2] Bluntzer, J.B.; Ostrosi, E.; Sagot, J.C.: Styling of cars: is there a relationship between the style of cars and the culture identity of a specific country? P I MECH ENG D J AUT, 229, 2015, 3851. https://doi.org/10.1177/0954407013517221

[3] Bo, L.; Xue, Y.M.; Wang, X.: Research on Design Innovation Approach to Enhance Product Value Based on Cost Control. SOCIAL SCIENCE, EDUCATION and HUMAN SCIENCE, 3, 2017, 1077-1081. https://doi.org/10.12783/dtssehs/icesd2017/11718

[4] Bohm, M.R.; Vucovich, J.P.; Stone, R.B.: Using a Design Repository to Drive Concept Generation. Journal of Computing \& Information Ence in Engineering, 8(1), 2008, 014502. https://doi.org/10.1115/1.2830844

[5] Bueyuekoezkan, G.; Gueleryuez, S.: A new integrated intuitionistic fuzzy group decision making approach for product development partner selection. COMPUT IND ENG, 102, 2016, 383-395. https://doi.org/10.1016/j.cie.2016.05.038 
[6] Chen, C.H.; Occena, L.G.; Fok, S.C.: CONDENSE: A concurrent design evaluation system for product design. INT J PROD RES, 39(3), 2001, 413-433.

[7] Chen, S., Chen, M.; Lyu, J.; Li, S.: Comfort Evaluation and Application of Office Chair Based on FAHP. Journal of Physics Conference Series, 2019 2nd International Symposium on Power Electronics and Control Engineering (ISPECE 2019), Tianjin, China,22-24 November 2019. https://doi.org/10.1088/1742-6596/1449/1/012063

[8] Cheutet, V.: 2D semantic sketcher for car aesthetic design. CPI2007 - Rabat, Maroc, 1, 2007, $1-13$.

[9] Choulier, D.; Fougères, A.J.; Ostrosi, E.: Developing multiagent systems for design activity analysis. COMPUT AIDED DESIGN, 59, 2015, 201-213. https://doi.org/10.1016/j.cad.2014.10.007

[10] Dong Y.F.; Peng Q.J.; Tan R.H.; Zhang J.L.; Zhang P.; Liu W.: Product Function Redesign Based on Extension Theory, Computer-Aided Design \& Applications, 18(1), 2021, 199-210. https://doi.org/10.14733/cadaps.2021.199-210

[11] Fougères, A.J.; Ostrosi, E.: Intelligent agents for feature modelling in computer aided design. Journal of Computational Design \& Engineering, 5(1), 2017, 19-40. https://doi.org/10.1016/j.jcde.2017.11.001

[12] Fu, Y.T.; Luo, S.J.: Style perception-oriented product family shape gene design. Computer Integrated Manufacturing Systems, 18(3), 2012, 449-457.

[13] Gero, J.S.: Special issue: Artificial intelligence in computer-aided design: Progress and prognosis. COMPUT AIDED DESIGN, 28(3), 1996, 153-154. https://doi.org/10.1016/00104485(96)86821-7

[14] Giovannini, A.; Aubry, A.; Panetto, H.; El Haouzi, H.; Pierrel, L.; Dassisti, M.: Anti-logicist framework for design-knowledge representation. ANNU REV CONTROL, 39, 2015, 144-157. https://doi.org/10.1016/j.arcontrol.2015.03.013

[15] Howard, T.J.; Culley, S.J.; Dekoninck, E.: Describing the creative design process by the integration of engineering design and cognitive psychology literature. DESIGN STUD, 29(2), 2008, 160-180. https://doi.org/10.1016/j.destud.2008.01.001

[16] Hyun, K.H.; Lee,J. H.; Kim, M.; Cho S.: Style synthesis and analysis of car designs for style quantification based on product appearance similarities. ADV ENG INFORM, 29(3), 2015, 483494. https://doi.org/10.1016/j.aei.2015.04.001

[17] Jie, G.; Han, S.Z.: A Study on the Extension AHP Method. SYSTEMS ENGINEERING, 20(5), 2002, 6-11. https://doi.org/10.1007/s11769-002-0073-1

[18] Jin, Y.; ISHINO, Y.: DAKA: design activity knowledge acquisition through data-mining. INT J PROD RES, 44(14), 2006, 2813-2837. https://doi.org/10.1080/00207540600654533

[19] Kapferer J.N.: Is there really no hope for local brands? Journal of Brand Management, 9(3), 2002, 163-170. https://doi.org/10.1057/palgrave.bm.2540066

[20] KARJALAINEN, T.M.: Strategic design language-transforming brand identity into product design elements. in Proceedings of the 10th International Product Development Management Conference. June 10-11 2003 Brussels.

[21] Kumar, P.; Tandon, P.: A paradigm for customer-driven product design approach using extended axiomatic design. J INTELL MANUF, 30, 2019, 589-603. https://doi.org/10.1007/s10845-016-1266-2

[22] Kyung H. H.; Lee, J.H.; Kim, M.: The gap between design intent and user response: identifying typical and novel car design elements among car brands for evaluating visual significance. J Intell Manuf, 28, 2017, 17-41.https://doi.org/10.1007/s10845-015-1176-8

[23] Li, W.Q.; Su, W.L.; Xiong, Y.: Research of conceptual design method based on multi-layers extension matter-element gene. Application Research of Computers, 25, 2008, 414-416.

[24] Li, Y.; Zhu, L.: Optimization of user experience in interaction design through a Taguchi-based hybrid approach. HUM FACTOR ERGON MAN, 29, 2018, 126-140. https://doi.org/10.1002/hfm.20765 
[25] Lieven, T.; Grohmann, B.; Herrmann, A.; Landwehr, J. R.; Tilburg M.: The effect of brand design on brand gender perceptions and brand preference. European Journal of Marketing, 49(2), 2015, 146-169. https://doi.org/10.1108/EJM-08-2012-0456

[26] Lin, M.C.: Using AHP and TOPSIS approaches in customer-driven product design process. COMPUT IND, 59, 2008, 17-31.

[27] Liu, C.Y.; Tong, L.I.: Developing Automatic Form and Design System Using Integrated Grey Relational Analysis and Affective Engineering. Applied sciences-Basel, 8(1), 2018, 2-22. https://doi.org/10.3390/app8010091

[28] Luo, S.J.; Fu, Y.T.; Korvenmaa, P.: A preliminary study of perceptual matching for the evaluation of beverage bottle design. INT I IND ERGONOM, 42(2), 2012, 219-232. https://doi.org/10.1016/j.ergon.2012.01.007

[29] Ma, L.; Destercke, S.; Wang, Y.: Online active learning of decision trees with evidential data. PATTERN RECOGN, 52, 2016, 33-45.https://doi.org/10.1016/j.patcog.2015.10.014

[30] Qian, Z.H.; Hong, Y.; Xu, C.Y.; Ren, L.Q.: A Biological Coupling Extension Model and Coupling Element Identification. J BIONIC ENG, 6(2), 2009, 186-195. https://doi.org/10.1016/S16726529(08)60106-7

[31] Randle, J.N.: The design and development of a new luxury sector automobile. P I MECH ENG D J TRA, 200(5), 2006, 1984-1988. https://doi.org/10.1243/PIME PROC 198620019802

[32] Ren, Y.: A Comparative Study of Intelligent Manufacturing between China and the Main Developed Countries. Industrial Economy Review, 8, 2015, 68-76.

[33] Stouffs, R.: Description grammars: Precedents revisited. Environment \& Planning B Urban Analytics \& City Science, 2, 2018, 1-21.https://doi.org/10.1177/0265813516667301

[34] Tang, H. ; Li, D. ; Wang, S. et al.: CASOA: An architecture for agent-based manufacturing system in the context of Industry 4.0. IEEE Access, 6, 2018, 12746-12754. https://doi.org/10.1109/ACCESS.2017.2758160

[35] Toni-Matti Karjalainen.: It looks like a Toyota Educational approaches to designing for visual brand recognition. Design case Study, 2(1), 2016, 1-21. https://doi.org/10.1177/0018726707078358

[36] Toni-Matti KARJALAINEN.: Strategic brand identity and symbolic design cues. INTERNATIONAL DESIGN CONFERENCE, 2, 2003, 1-13.

[37] Vaidya, O.S.; Kumar, S. Analytic hierarchy process: An overview of applications. EUR J OPER RES, 169, 2006, 1-29. https://doi.org/10.1016/j.ejor.2004.04.028

[38] Wang, Z.; Liu, W.; Yang, M.; Han, D.: A Multi-Objective Evolutionary Algorithm Model for Product Form Design Based on Improved SPEA2. Applied Sciences-Basel, 9(14), 2019, 29-44. https://doi.org/10.3390/app9142944

[39] Yang, C.; Wen, C.: Proceedings of the 2nd International Symposium on Extenics and Innovation Methods. HEREDITY, 4(3), 2015, 313-325. https://doi.org/10.1038/hdy.1950.24

[40] Yang, G.W.: Intelligentized and Modeling Conceptual Design Based on the Analysis of Matter Element Dynamic System. COMPUT APPL ENG EDUC, 16, 2005, 112-116. https://doi.org/10.1081/CEH-200044273

[41] Yang W.; Su J.; Qiu K.; Zhang X.; Zhang S.: Research on Evaluation of Product Image Design Elements Based on Eye Movement Signal. In Engineering Psychology and Cognitive Ergonomics, HCII 2019. Lecture Notes in Computer Science, 11571, 2019. https://doi.org/10.1007/978-3-030-22507-017

[42] Zhang, S.Y.; Gu, Y.; Liu, X.J.; Tan, J.R.: A knowledge push technology based on applicable probability matching and multidimensional context driving. Frontiers of Information \& Electronic Engineering, 19, 2018, 235-245.https://doi.org/10.1631/FITEE.1700763

[43] Zhang, Y.; Zhong, S.S.; Li, J.: Extension methods in case-based reasoning and applications. Journal of Jilin University(Engineering and Technology Edition), 39, 2009, 424-429. https://doi.org/10.1109/ICICSE.2009.69

[44] Zhao, Y.: Study of Conceptual Design of Extension for Mechanical Products. Engineering Science, 3(5), 2001, 67-71. 
[45] Zhao, Y.W.: Research in the Method of Intelligent Conceptual Design Based on the Extension Theory. PhD thesis, ShangHai University, ShangHai, Feb. 2005.

[46] Zou, C.W.; Zhang, S.Y.; Ying, G.D.; Qiu, J.B.: Extension matter-element model of part for product variant design. Computer Integrated Manufacturing System, 14(9), 2008, 14-20. https://doi.org/10.1016/j.commatsci.2008.03.016 